\title{
Food ingredients from the marine environment. Marine biotechnology meets food science and technology
}

\author{
loannis S. Boziaris* \\ Department of Ichthyology and Aquatic Environment, School of Agricultural Sciences, University of Thessaly, Volos, Greece
}

\section{Edited by:}

Donatella De Pascale, National

Research Council- CNR, Italy

\section{Reviewed by:}

Laura Núñez Pons, University of

Hawai'i at Manöa, USA

Avinash Mishra, Central Scientific

Industrial Research - Central Salt \&

Marine Chemicals Research

Institute [CSMCRI], India

*Correspondence:

loannis S. Boziaris, Department of Ichthyology and Aquatic

Environment, School of Agricultural

Sciences, University of Thessaly,

Fitoko street, 38446, Nea lonia,

Volos, Greece

e-mail: boziaris@uth.gr
Marine environment affords a plethora of bioactive compounds with unique properties and remarkable potential for biotechnological applications. A lot of those compounds can be used by the food industry as natural preservatives, pigments, stabilizers, gelling agents, and others, while others exhibit beneficial effects and can be used as functional food ingredients, nutraceuticals, dietary supplements and prebiotics. Interdisciplinary approach is required to increase our knowledge, explore the potential of marine environment and produce value-added food for all.

\section{Keywords: marine biotechnology, food technology, bioactive compounds, functional food, nutraceuticals, natural} food additives

\section{INTRODUCTION}

As food scientist/microbiologist I have the perception that the marine environment is just a source of food for humans, just like it happens for the terrestrial environment under the practices of agriculture. Marine environment contribution to human food supply is as old as human existence in the planet and still most of the anthropogenic activities take place around the world's coasts. Humans have been using aquatic environments to collect their food from prehistoric periods with fishing being an older activity than agriculture. In our days, fisheries and aquaculture provides almost the $50 \%$ of the animal protein supply (FAO, 2014).

When I joined Academia at the Department of Ichthyology and Aquatic Environment at the University of Thessaly, Greece, I had the opportunity to meet and cooperate with colleagues from scientific disciplines like marine biology and ecology. Gradually I realized that apart from the contribution of marine environment to the world's food supply, the seas offer a far richer variety of useful constituents to be used in foods with a higher potential compared to the terrestrial environment. Marine environment, covering more than $70 \%$ of the earth's surface, hosts the greatest diversity of life which most of it is still unexplored. The ability of aquatic organisms to survive in a wide range of environmental conditions makes them to develop an enormous reservoir of bioactive compounds with unique properties and great potential for biotechnological applications.

Recently, there has been a growing interest for functional food ingredients, nutraceuticals, probiotic, prebiotic, and various dietary supplements (Shahidi, 2009). Nutraceutical comes from the words "nutrition" and "pharmaceutical." Nutraceutical is a product that is generally sold in medicinal forms that provides health and medical benefits, including the prevention and/or treatment of disease. Functional foods are those that can give specific medical or physiological benefit, other than a purely nutritional effect. Functional foods usually contain ingredients with known bioactive compounds in defined amounts and they provide a clinically proven health benefit. Furthermore, probiotic is currently used to name ingested microorganisms associated with beneficial effects to humans or animals, while prebiotics is a general term to refer to compounds that induce the growth and/or activity of microorganisms that contribute to the well-being of their host, like the beneficial microorganisms that colonize the human gastrointestinal track.

The manufacturing of foods that provide additional health benefits to the consumer is an aspect of increasing interest for the modern society (Siegrist et al., 2008). Additionally, consumers in our days demand minimally processed food for maximum nutrient retention, without the addition of chemical preservatives while on the other hand the foods need to be safe, with prolonged shelf-life and easy to use (Gould, 1996). To fulfill these requirements, natural compounds from various terrestrial or aquatic sources and biomolecules that exert antimicrobial, antioxidant, prebiotic, anticoagulant, antitumor, antiviral, anti-inflammation, and others, actions have to be employed by the food industry. It seems that finally, the father of western medicine Hippocrates' thoughts, expressing that food has to be our medicine, seem to have become finally the guides for our modern practices.

\section{FOOD RELATED COMPOUNDS FROM MARINE ENVIRONMENT}

The seas, while they remain relatively unharmed by negative anthropogenic activities, represent a gigantic reservoir of bioactive compounds. A plethora of compounds such as enzymes, proteins, peptides, polysaccharides, polyunsaturated fatty acids (PUFA), phenolics, pigments and other secondary metabolites 
from various sources, such as prokaryotes, micro- and macroalgae, seaweeds, crustaceans, sponges and other invertebrates as well as various vertebrates can be useful to the food industry in a number of applications (Holdt and Kraan, 2011; Freitas et al., 2012; Murray et al., 2013; Dewapriya and Kim, 2014) (Table 1).

Marine organisms are the main source of $\omega-3$ fatty acids, which exert beneficial effect against chronic diseases (RubioRodríguez et al., 2010). PUFA especially, eicosapentaenoic and docosahexaenoic $\omega-3$ fatty acids are considered nutraceuticals, and apart from fish such as herring, mackerel, sardine and salmon, which are considered their primary source, other marine organisms such as bacteria, microalgae, dinoflagellates, and fungi can also provide them (Dewapriya and Kim, 2014).

Polysaccharides have numerous applications in food technology. Alginate, carrageenans and agar from various seaweeds can form hydrocolloids and are used as gelling agents, stabilizers and edible films in many food products, while others, e.g., fucans/fucanoids from various seaweeds and sea vegetables exhibit various beneficial actions, such as antioxidant, anticancer, anti-arteriosclerosi, anti-tumor, and others (Holdt and Kraan, 2011; Kim and Li, 2011). Chitin, chitosan and their derivatives, mainly from crustaceans, have a range spectrum of applications including the use as gelling and emulsifying agents, natural antimicrobial preservatives, edible antimicrobial films etc. (Shahidi et al., 1999; Hayes et al., 2008; Kapetanakou et al., 2014). Fibers, so important in modern diet, can be provided by seaweeds and other marine organisms (Holdt and Kraan, 2011; Freitas et al., 2012).
Various proteins, peptides and enzymes of marine origin have already application in the food industry, like collagen and gelatin, while others have potential applications. Bioactive peptides from fish, mussels, microalgae, squid etc. can act as natural antioxidants with the potential to replace less desirable chemical additives (Ngo et al., 2012). Numerous enzymes which can function at extreme conditions compared to enzymes from terrestrial sources are disposed in marine organisms with novel application for the food industry (Shahidi and Janak Kamil, 2001; Trincone, 2011; Zhang and Kim, 2012). Additionally, nutritional value of seaweeds proteins in terms of essential amino acids composition is higher than cereals and vegetables (Holdt and Kraan, 2011), showing the potential of seaweeds as human food in the future.

Marine pigments exhibit a great potential for use as antioxidants and natural food colorants. Carotenoids, astaxanthin, fucoxanthin and other compounds from seaweeds exhibit antioxidant and other activities and can be used by the food industry (Ngo et al., 2011; Pangestuti and Kim, 2011), while other pigments from marine bacteria, microalgae and plants can be used as natural food colorants (Holdt and Kraan, 2011; Baghel et al., 2014). Various phenolic compounds, tannins, terpenes etc., from seaweeds and other marine plants show antimicrobial and antioxidant activity (Kontiza et al., 2008; Onofrejova et al., 2010; Holdt and Kraan, 2011; Cox et al., 2013) same as the phenolics from terrestrial plants (Proestos et al., 2006).

Apart from bioactive compounds from various organisms, marine microorganisms have also a great potential regarding food science and technology. They participate in fermentation of marine foods (Dewapriya and Kim, 2014; Tanasupawat and

\section{Table 1 | Examples of several compounds from marine organisms, their properties and their potential uses in the food industry.}

\begin{tabular}{lll}
\hline Type & Origination & Functionality and health benefits \\
\hline PUFAs & $\begin{array}{l}\text { Marine bacteria, microalgae, } \\
\text { dinoflagellates, fungi, fish }\end{array}$ & $\begin{array}{l}\text { Cronic diseases (e.g., cancer, heart diseases, } \\
\text { atherosclerosis asthma, arthritis, vascular } \\
\text { disease, thrombosis, immune-inflammatory } \\
\text { processes, tumor proliferation) }\end{array}$ \\
Alginate, carrageenans, agar & Seaweeds & Gelling agents, stabilizers,
\end{tabular}

\begin{tabular}{|c|c|c|}
\hline Alginate, carrageenans, agar & Seaweeds & Gelling agents, stabilizers, \\
\hline Fucans, fucanoids & Seaweeds, sea vegetables & $\begin{array}{l}\text { Antioxidant, anticancer, anti-arteriosclerosis, } \\
\text { anti-tumor activity etc }\end{array}$ \\
\hline $\begin{array}{l}\text { Proteins, peptides and amino } \\
\text { acids }\end{array}$ & Seaweeds, fish by-products & $\begin{array}{l}\text { Diabetes, cancer, and AIDS and prevention of } \\
\text { vascular diseases }\end{array}$ \\
\hline Bioactive peptides & $\begin{array}{l}\text { Fish, mussels, microalgae, squid } \\
\text { etc. }\end{array}$ & Antioxidant activity \\
\hline $\begin{array}{l}\text { Chitin, chitosan and their } \\
\text { derivatives }\end{array}$ & Crustaceans & Antimicrobial activity \\
\hline
\end{tabular}

Fibers

Carotenoids, astaxanthin, fucoxanthin

Bacterial pigments

Phenolic compounds tannins, terpenes etc Marine microorganisms

Seaweeds and other marine
organisms
Seaweeds
Marine bacteria
Seaweeds and other marine
plants
Marine environment

Prebiotic compounds

Antioxidant and natural pigments

Antimutagenic and anticancer effect

Antimicrobial and antioxidant activity

Food fermentation, probiotic activity

\section{Potential food application}

Nutraceuticals, functional foods, food supplements

Gelling and emulsifying agents, edible films etc.

Nutraceuticals

Functional food, food supplements, food

Functional foods, nutraceutical, natural food preservatives

emulsifying agents, edible antimicrobial films, natural food preservatives

Food supplements nutraceuticals functional foods Natural preservatives and food colorants

Functional foods, nutraceutical, natural food colorants

Natural food preservatives

Starter cultures, probiotic 
Visessanguan, 2014), can produce various compounds to be used as natural food additives and/or functional ingredients and can also be exploited as probiotics for use in human or productive animals diet (Kim et al., 2012; Dewapriya and Kim, 2014; Prieto et al., 2014).

\section{EXPLOITATION OF MARINE ORGANISMS FOR FOOD CONSTITUENTS}

So far the exploitation of bioactive ingredients from the sea is limited. Biodiversity in the seas has not been fully explored yet, mostly due to the difficulties that arise in investigation of marine organisms in contrast to the terrestrial environment. A plethora of bioactive ingredients have been discovered, studied and exploited from terrestrial organisms, mostly plants, which exhibit mainly antimicrobial and/or antioxidant activity.
Numerous research projects aiming to approach the use of natural preservatives from plants have been funded either from European Union or other Organizations and National programs. Instead, research programs focusing on bioactive compounds from the marine environment has only initiated in the last decade, with a few ongoing research initiatives.

To exploit all the above-mentioned potential from the seas, an interdisciplinary approach is imperative. Disciplines like chemistry, microbiology, bioprocessing engineering, food technology, and others, can offer methodologies to optimize isolation, identification, purifications, production and application of the unique marine bioactive compounds for the production of value-added food. A flow diagram of potential actions and disciplines that might be required is shown in Figure 1 .

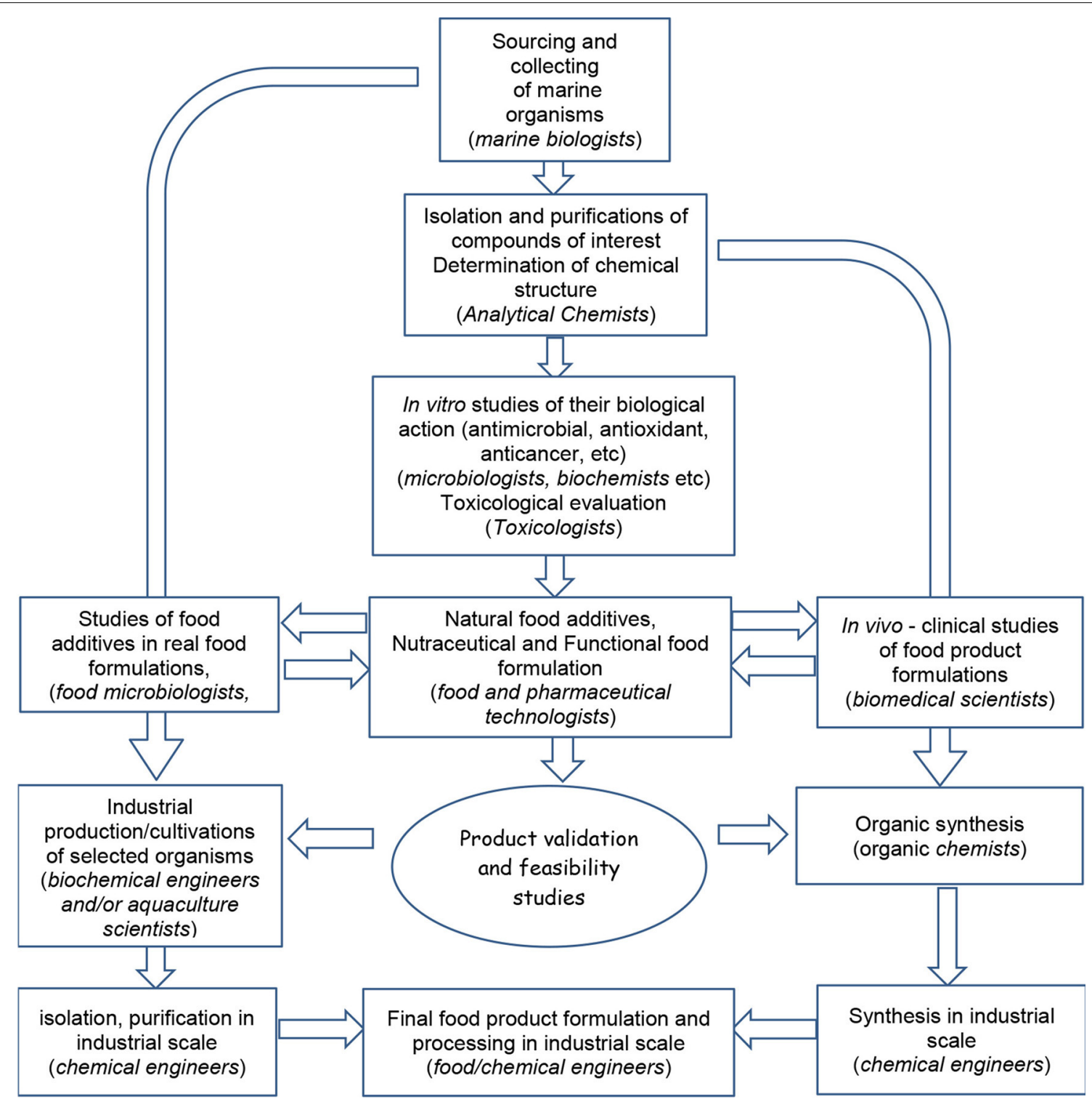

FIGURE 1 | Potential actions and disciplines that might be required for the optimal exploitation of marine bioactive compounds for food use. 
Additionally, the implementation of modern techniques and tools of molecular biology, genomics, proteomics, and others can also widen the horizons of our knowledge about the marine organism and the huge thesaurus of genes and metabolic functions they include (Imhoff et al., 2011; Hartmann et al., 2014). Indeed, proteomics can identify proteins with potential applications to food biotechnology, while the elucidation of genetic information as well as the metabolic activities of candidate organisms can aid toward the large scale production of useful food constituents.

Concluding, the potential of marine environment as reservoir for useful bioactive molecules is enormous. Its capability to provide food constituents seems to be more than enough to aid us achieve the required food security. Application of modern technologies for efficient and sustainable production of value-added food products will be a future challenge that the scientific and technological society has to deal with for a more prosperous future.

\section{REFERENCES}

Baghel, R. S., Kumari, P., Reddy, C. R. K., and Jha, B. (2014). Growth, pigments, and biochemical composition of marine red alga Gracilaria crassa. J. Appl. Phycol. 26, 2143-2150. doi: 10.1007/s10811-014-0250-5

Cox, S., Turley, G. H., Rajauria, G., Abu-Ghannam, N., and Jaiswal, A. M. (2013). Antioxidant potential and antimicrobial efficacy of seaweed (Himanthalia elongata) extract in model food systems. J. Appl. Phycol. 26, 1823-1831. doi: 10.1007/s10811-013-0215-0

Dewapriya, P., and Kim, S.-K. (2014). Marine microorganisms: an emerging avenue in modern nutraceuticals and functional foods. Food Res. Int. 56, 115-125. doi: 10.1016/j.foodres.2013.12.022

FAO. (2014). Contribution of Fisheries to Food Security. Availabla online at: http:// www.fao.org/fishery/topic/12367/en (Accessed 25 July, 2014)

Freitas, A. C., Rodrigues, D., Rocha-Santos, T. A. P., Gomes, A. M. P., and Duarte, A. C. (2012). Marine biotechnology advances towards applications in new functional foods. Biotechnol. Adv. 30, 1506-1515. doi: 10.1016/j.biotechadv.2012.03.006

Gould, G. W. (1996). Industry perspectives on the use of natural antimicrobials and inhibitors for food applications. J. Food Protect. (Suppl.) 59, 82-86.

Hartmann, E. M., Durighello, E., Pible, O., Nogales, B., Beltrametti, F., Bosch, R., et al. (2014). Proteomics meets blue biotechnology: a wealth of novelties and opportunities. Mar. Genomic 17, 35-42. doi: 10.1016/j.margen.2014. 04.003

Hayes, M., Carney, B., Slater, J., and Bróck, W. (2008). Mining marine shellfish wastes for bioactive molecules: chitin and chitosan-part B: applications. Biotechnol. J. 3, 878-889. doi: 10.1002/biot.200800027

Holdt, S. L., and Kraan, S. (2011). Bioactive compounds in seaweed: functional food applications and legislation. J. Appl. Phycol. 23, 543-597. doi: 10.1007/s10811-010-9632-5

Imhoff, J. F., Labes, A., and Wiese, J. (2011). Bio-mining the microbial treasures of the ocean: new natural products. Biotechnol. Adv. 29, 468-482. doi: 10.1016/j.biotechadv.2011.03.001

Kapetanakou, A. E., Manios, S. G., and Skandamis, P. N. (2014). "Application of edible films and coatings in foods," in Novel Food Preservation and Microbial Assessment Techniques, ed I. S. Boziaris (Boca Raton, FL: Taylor \& Francis, CRC Press), 237-273.

Kim, S.-K., Bhatnagar, I., and Kang, K.-H. (2012). Development of marine probiotics: prospects and approach. Adv. Food Nutr. Res. 64, 353-362. doi: 10.1016/B978-0-12-416003-3.00023-8

Kim, S.-K., and Li, Y.-X. (2011). Medicinal benefits of sulfated polysaccharides from sea vegetables. Adv. Food Nutr. Res. 64, 391-402. doi: 10.1016/B978-0-12387669-0.00030-2

Kontiza, I., Stavri, M., Zloh, M., Vagias, C., Gibbons, S., and Roussis, V. (2008). New metabolites with antibacterial activity from the marine angiosperm Cymodocea nodosa. Tetrahedron 64, 1696-1702. doi: 10.1016/j.tet.2007. 12.007
Murray, P. M., Moane, S., Collins, C., Beletskaya, T., Thomas, O. P., Duarte, A. W. F., et al. (2013). Sustainable production of biologically active molecules of marine based origin. N. Biotechnol. 30, 839-850. doi: 10.1016/j.nbt.2013. 03.006

Ngo, D.-H., Voa, T.-S., Ngo, D.-N., Wijesekarac, I., and Kim, S.-K. (2012). Biological activities and potential health benefits of bioactive peptides derived from marine organisms. Int. J. Biol. Macromol. 51, 378-383. doi: 10.1016/j.ijbiomac.2012.06.001

Ngo, D.-H., Wijesekara, I., Vo, T.-S., Van Ta, Q., and Kim, S.-K. (2011). Marine food-derived functional ingredients as potential antioxidants in the food industry: an overview. Food Res. Int. 44, 523-529. doi: 10.1016/j.foodres.2010.12.030

Onofrejova, L., Vasickova, J., Klejdus, B., Stratil, P., Misurcovac, L., Kracmar, S., et al. (2010). Bioactive phenols in algae: the application of pressurized-liquid and solid-phase extraction techniques. J. Pharm. Biomed. Anal. 51, 464-470. doi: 10.1016/j.jpba.2009.03.027

Pangestuti, R., and Kim, S. (2011). Biological activities and health benefit effects of natural pigments derived from marine algae. J. Funct. Foods 3, 155-266. doi: 10.1016/j.jff.2011.07.001

Prieto, M. L., O’Sullivan, L., Tan, S. P., McLoughlin, P., Hughes, H., Gutierrez, M., et al. (2014). In Vitro assessment of marine Bacillus for use as livestock probiotics. Mar. Drugs 12, 2422-2445. doi: 10.3390/md12052422

Proestos, C., Boziaris, I. S., Nychas, G.-J. E., and Komaitis, M. (2006). Analysis of flavonoids and phenolic acids in Greek aromatic plants. Investigation of their antioxidant capacity and antimicrobial activity. Food Chem. 95, 664-671. doi: 10.1016/j.foodchem.2005.01.049

Rubio-Rodríguez, N., Beltrán, S., Jaime, I., Diego, S. M., Sanz, M. T., and Carballido, J. R. (2010). Production of omega-3 polyunsaturated fatty acid concentrates: a review. Innov. Food Sci. Emerg. Technol. 11, 1-12. doi: 10.1016/j.ifset.2009.10.006

Shahidi, F. (2009). Nutraceuticals and functional foods: whole versus processed foods. Trends Food Sci. Technol. 20, 376-387. doi: 10.1016/j.tifs.2008. 08.004

Shahidi, F., Arachchi, J. K. V., and Jeon, Y.-J. (1999). Food applications of chitin and chitosans. Trends Food Sci. Technol. 10, 37-51. doi: 10.1016/S09242244(99)00017-5

Shahidi, F., and Janak Kamil, Y. V. A. (2001). Enzymes from fish and aquatic invertebrates and their application in the food industry. Trends Food Sci. Technol. 12, 435-464. doi: 10.1016/S0924-2244(02)00021-3

Siegrist, M., Stampfli, N., and Kastenholz, H. (2008). Consumer's willingness to buy functional foods. The influence of carrier, benefit and trust. Appetite 51, 526-529. doi: 10.1016/j.appet.2008.04.003

Tanasupawat, S., and Visessanguan, W. (2014). "Fish fermentation," in Seafood Processing. Technology, Quality and Safety, ed I. S. Boziaris (Chichester: Wiley-Blackwell; IFST Advances in Food Science Series), 177-199.

Trincone, A. (2011). Marine biocatalysts: enzymatic features and applications. Mar. Drugs 9, 478-499. doi: 10.3390/md9040478

Zhang, C., and Kim, S.-K. (2012). Application of marine microbial enzymes in the food and pharmaceutical industries. Adv. Food Nutr. Res. 64, 423-435. doi: 10.1016/B978-0-12-416003-3.00028-7

Conflict of Interest Statement: The author declares that the research was conducted in the absence of any commercial or financial relationships that could be construed as a potential conflict of interest.

Received: 09 September 2014; accepted: 05 November 2014; published online: 21 November 2014.

Citation: Boziaris IS (2014) Food ingredients from the marine environment. Marine biotechnology meets food science and technology. Front. Mar. Sci. 1:66. doi: 10.3389/ fmars.2014.00066

This article was submitted to Marine Biotechnology, a section of the journal Frontiers in Marine Science.

Copyright (C) 2014 Boziaris. This is an open-access article distributed under the terms of the Creative Commons Attribution License (CC BY). The use, distribution or reproduction in other forums is permitted, provided the original author(s) or licensor are credited and that the original publication in this journal is cited, in accordance with accepted academic practice. No use, distribution or reproduction is permitted which does not comply with these terms. 